\title{
Effect of Intra Articular Tranexamic Acid Use on Post-Operative Blood Loss in Unilateral Primary Total Knee Arthroplasty (TKA)
}

Jagseer Singh $^{1}$, Harpreet Kaur ${ }^{2 *}$

\author{
${ }^{1}$ Associate Professor, Department of Orthopaedics, Adesh Institute of Medical Sciences and Research, Bathinda, Punjab, India \\ ${ }^{2}$ Professor, Department of Physiology, Adesh Institute of Medical Sciences and Research, Bathinda, Punjab, India
}

DOI: $10.36347 /$ sjams.2020.v08i08.007

| Received: 01.08.2020 | Accepted: 08.08.2020 | Published: 18.08.2020

*Corresponding author: Dr. Harpreet Kaur

Abstract

Original Research Article

Osteoarthritis of knee leads to disability and effects quality of life due to pain and deformity in advanced cases. Knee replacement is one of most successful surgery for osteoarthritis knee. This surgery improves pain and function of patient but is associated with substantial blood loss during and after the surgery. Tranexamic acid is commonly used to decrease post-operative blood loss by various routes i.e. oral, intravenous and intra-articular .Objective of study is to evaluate the effect of intra-articular Tranexamic acid on post-operative blood loss after unilateral primary total knee arthroplasty (TKA). A total of 50 patients of either gender planned to undergo unilateral total knee replacement (TKR) were enrolled in each of the two groups. In group A (Control group) no intra articular drug is injected. In Group B (study group), patients were given 2 gram intra articular Tranexamic acid. All patients were followed up to 72 hours from completion of surgery. Blood collection in negative suction drain was noted after every 24 hours. In the study group, the post-operative drainage blood loss was $550.36 \pm 72.81$ significantly less $(\mathrm{p}<0.05)$ than those in the control group that was 1008.12 \pm 111.62 . Intra-articular application of Tranexamic Acid is effective in decreasing the drainage blood loss after primary TKA treatment.

Keywords: Osteoarthritis, blood loss, Tranexamic Acid, Total Knee Arthroplasty (TKA), unilateral.

Copyright @ 2020: This is an open-access article distributed under the terms of the Creative Commons Attribution license which permits unrestricted use, distribution, and reproduction in any medium for non-commercial use (NonCommercial, or CC-BY-NC) provided the original author and source are credited.

\section{INTRODUCTION}

Osteoarthritis is one of the most common joint disorders and a major cause of disability worldwide. It results in activity limitations and affects the quality of life [1]. Its prevalence increases with age and generally affects women more frequently than men [2]. For patients suffering from end-stage knee osteoarthritis, total knee arthroplasty provides reliable outcomes with respect to pain relief, increased mobility and improved quality of life [3]. But TKA is often associated with substantial blood loss and increases the frequency of blood transfusion requirements [4]. Blood transfusions athough effective in correcting anaemia can increase the economic burden on the patients. Allogenic blood transfusions are also associated with various risks and complications like infections, cardiac arrhythmias, fluid overload and prolonged hospitalization [5, 6]. Blood loss and requirements of blood transfusions associated with TKA should be reduced to avoid unnecessary economic burden and complications.

Several blood conservation methods have been used during TKA [4]. Tranexamic Acid is one of the strategies used for blood conservation during TKA and can effectively reduce blood loss and transfusion rates in TKA. Although Tranexamic Acid can also be administered orally but topical application and intravenous infusion remains the major route of administration [7-11]. Being synthetic amino acid, Tranexamic acid functions by competitive inhibition of plasminogen conversion into plasmin, thus promoting clot stabilization $[12,13]$. Tranexamic acid effects the hemostasis by inhibiting fibrinolysis [7, 14]. In primary unilateral TKA, topical intra-articular Tranexamic Acid successfully reduces the blood loss and does not appear to increase the risk of thromboembolic adverse effects [15]. While many studies have focused on the effectiveness of TXA reducing intra and postoperative blood loss there is a need for further studies focusing on its intra-articular administration [16].

\section{ОВJECTIVE}

The objective of the study was to evaluate the effect of intra-articular use of Tranexamic Acid on drainage blood loss after unilateral primary total knee arthroplasty (TKA). 


\section{Material ANd Methods}

A total of 50 patients with indications of unilateral TKA treated at Orthopaedics Department of Adesh Institute of Medical Sciences and Research (AIMSR), Bathinda, Punjab were selected from February 2020 to July 2020. The selected patients were informed about the project and informed consent was taken. The study was approved by the Institutional Ethical Committee of the Institution. Patients were divided into two groups: those in which no substance was used (Group A Control) and those with intra articular application of Tranexamic Acid (Group B study).

\section{Inclusion Criteria}

Patients of age 45-70 years of either gender presenting with Osteoarthritis knee and planned to undergo unilateral primary TKA.

\section{Exclusion Criteria}

Patients with major deformities that would lead to more bone cuts or release of a more extensive area of soft tissue, patients who had undergone previous surgeries of the same knee, INR $>2$, taking atorvastatins or aspirin, cardiac disease, Systemic lupus erthymatosis, IV drug abuser, alcoholics, thalasemia or leukemia, thrombocytopenia, idiopathic thrombocytopenic purpura, deep vein thrombosis or prior pulmonary embolism were excluded.

\section{Procedure}

All patients who met inclusion criteria were divided into two groups. Group A (control group) no intra articular drug was given during surgery. In Group B (study group) $2 \mathrm{gm}$ intra-articular Tranexamic acid was injected during surgery. All surgeries were done under spinal anaesthesia by a single surgical team. Standard midline vertical skin incision was used. Knee joint was exposed through medial parapatellar approach. Tourniquet was inflated to pressure $350 \mathrm{mmHg}$ before skin incision. Bone cuts were taken and implant trailing done. Bone surfaces washed with pulse lavage and cemented Prosthesis was inserted. Wound was stitched in layers over negative suction drain. 2 gram Tranexamic acid diluted in $50 \mathrm{ml}$ normal saline was injected intra-articularly. Tourniquet was released after closure of wound. Drain was clamped for 15 minutes for absorption of Tranexamic acid. In Group A, $50 \mathrm{ml}$ normal saline was injected intraarticularly. Patient was shifted to post-surgical care facility. Patients were followed up for next 72 hours. Blood loss (collected in negative suction drain) was noted 24 hourly for next 72 hours.

\section{Data Analysis}

Data was analysed using Open Epi software. The significance level adopted for all comparisons was $5 \%$. Mean and standard deviations were calculated for age and blood loss.

\section{RESUlTS}

Mean age of patients in Group A (Control group) was $58.72 \pm 6.97$ years, in Group B (Tranexamic acid) was $59.04 \pm 7.39$ years. Male to female ratio in Group A was 9:16 and in Group B was 10:15. There were $6(24 \%)$ hypertensive patients in group A and $5(20 \%)$ in Group B and $2(8 \%)$ diabetic patients in Group A and 3(12\%) in Group B. Table 1.

The mean blood loss during first 24 hours was $388.8 \pm 57.41 \mathrm{ml}$ in Group A and $219.44 \pm 39.69 \mathrm{ml}$ in Group B. The difference was statistically significant $(\mathrm{p}<0.05)$. The mean blood loss during next 24 hours was $357.88 \pm 57.31 \mathrm{ml}$ in Group A and $194.52 \pm 24.00 \mathrm{ml}$ in Group B. The difference was significant $(\mathrm{P}<0.05)$. The mean blood loss during next 24 hours was $261.44 \pm 26.59 \mathrm{ml}$ in Group A and $136.44 \pm 27.17 \mathrm{ml}$ in Group B. The difference was significant in Group A and Group B $(p<0.05)$. The mean drainage total blood loss during 72 hours was $1008.12 \pm 111.62 \mathrm{ml}$ in Group A (Control group) and $550.36 \pm 72.81 \mathrm{ml}$ in Group B (Tranxemic acid). The difference was significant in Group A and Group B (p<0.05). (Table2).

Table-1: Demographics of patients in two groups

\begin{tabular}{|c|c|c|}
\hline & Control & Tranexamic acid \\
\hline Number & 25 & 25 \\
\hline Age (years) & $58.72 \pm 6.97$ & $59.04 \pm 7.39$ \\
\hline Male & 9 & 10 \\
\hline Female & 16 & 15 \\
\hline Hypertension & $6(24 \%)$ & $5(20 \%)$ \\
\hline Diabetes & $2(8 \%)$ & $3(12 \%)$ \\
\hline
\end{tabular}

Table-2: Comparison of blood loss between two groups (ml)

\begin{tabular}{|c|c|c|c|}
\hline & Control & Tranexamic acid & p-value \\
\hline N & 25 & 25 & \\
\hline First 24 hour & $388.8 \pm 57.41$ & $219.44 \pm 39.69$ & $<0.05$ \\
\hline Second 24hour & $357.88 \pm 57.31$ & $194.52 \pm 24.00$ & $<0.05$ \\
\hline Third 24 hours & $261.44 \pm 26.59$ & $136.44 \pm 27.17$ & $<0.05$ \\
\hline Total blood loss(after 72 hours) & $1008.12 \pm 111.62$ & $550.36 \pm 72.81$ & $<0.05$ \\
\hline
\end{tabular}




\section{DISCUSSION}

Many perioperative blood loss management strategies have been used previously and the use of Tranexamic Acid is one of them. In this study, we evaluated the effect of intra-articular administration of Tranexamic Acid on reducing the blood loss after unilateral primary TKA. The intra-articular administration of $2 \mathrm{~g}$ of Tranexamic Acid was effective in reducing the blood loss after TKA as compared to the control group in which no intra-articular drug was injected during surgery and the difference was statistically significant $(\mathrm{p}<0.05)$.

The findings of this study are consistent with the previously published studies. Guerreiro et al. concluded that in addition to reducing bleeding, topical TXA improved pain and increased flexion gain in the first hours after TKA [17]. According to Wong $\mathrm{J}$ et al. At the conclusion of a total knee arthroplasty with cement, topical application of tranexamic acid directly into the surgical wound reduced postoperative bleeding by $20 \%$ to $25 \%$, or 300 to $400 \mathrm{~mL}$, resulting in $16 \%$ to $17 \%$ higher postoperative hemoglobin levels compared with placebo, with no clinically important increase in complications being identified in the treatment groups [18]. The meta-analysis conducted by Yang ZG et al. shows that the use of tranexamic acid for patients undergoing total knee arthroplasty is effective and safe for the reduction of blood loss. The amount of blood loss and the number of blood transfusions per patient were significantly less and the proportion of patients who required a blood transfusion was smaller in the tranexamic acid group compared with the placebo group. No significant difference in prothrombin time activated partial thromboplastin time, deep-vein thrombosis, and pulmonary embolism was detected between the tranexamic acid group and the placebo group[19]. Yen et al. found that the mean blood loss was $1131 \pm 336 \mathrm{ml}$ in placebo group while $921 \pm 252 \mathrm{ml}$ with intravenous Tranexamic acid while $795 \pm 231 \mathrm{ml}$ with intra articilar Tranexamic acid. $(\mathrm{p}<0.01)[20]$.

\section{Conclusion}

Intra-articular application of Tranexamic Acid is effective in decreasing the drainage blood loss after primary TKA.

\section{REFERENCES}

1. Clemence Palazzo, Christelle Nguyen, MarieMartineLefevre-Colau, FrançoisRannou, SergePoiraudeau. Risk factors and burden of osteoarthritis. Annals of Physical and Rehabilitation Medicine, June. 2016;59(3):134138.

2. Pal CP, Singh P, Chaturvedi S, Pruthi KK, Vij A. Epidemiology of knee osteoarthritis in India and related factors. Indian J Orthop. 2016;50(5):518522.
3. Li JW, Ma YS, Xiao LK. Postoperative Pain Management in Total Knee Arthroplasty. Orthop Surg. 2019;11(5):755-761.

4. Qiang Lu, Hao Peng, Guan-jin Zhou, Dong Yin. Perioperative Blood Management Strategies for Total Knee Arthroplasty.Orthopaedic Surgery. 2018;10:8-16.

5. Friedman R, Homering M, Holberg G, Berkowitz SD. Allogeneic blood transfusions and postoperative infections after total hip or knee arthroplasty. J Bone Joint Surg Am. 2014;96(4):272-278.

6. Maempel JF, Wickramasinghe NR, Clement ND, Brenkel IJ, Walmsley PJ. The pre-operative levels of haemoglobin in the blood can be used to predict the risk of allogenic blood transfusion after total knee arthroplasty. Bone Joint J. 2016;98-B(4):490497.

7. Gomez- Barrena E, Ortega- Andreu M, PadillaEguiluz NG, Perez- Chrzanowska H, FigueredoZalve R. Topical intra- articular compared with intravenous tranexamic acid to reduce blood loss in primary total knee replacement: a double- blind, randomized, controlled, noninferiority clinical trial. J Bone Joint Surg Am. 2014, 96: 1937-1944.

8. Lin SY, Chen CH, YC F, Huang PJ, Chang JK, Huang HT. The efficacy of combined use of intra-articular and intravenous tranexamic acid on reducing blood loss and transfusion rate in total knee arthroplasty. J Arthroplasty. 2015, 30: 776780.

9. Pitta M, Zawadsky M, Verstraete R, Rubinstein A. Intravenous administration of tranexamic acid effectively reduces blood loss in primary total knee arthroplasty in a 610- patient consecutive case series. Transfusion. 2016, 56: 466-471.

10. Serrano ML, Goudarz MK, Caceres L, Lee YY, Gonzalez Della Valle A. Topical tranexamic acid may improve early functional outcomes of primary total knee arthroplasty. J Arthroplasty. 2016, 31: 1449-1452.

11. Alipour M, Tabari M, Keramati M, Zarmehri AM, Makhmalbaf H. Effectiveness of oral Tranexamic Acid administration on blood loss after knee arthroplasty: Arandomized clinical trial. Transfus Apher Sci,2013,49:574-577. Transfus

12. Danninger T, Memtsoudis SG. Tranexamic acid and orthopedic surgery - the search for the holy grail of blood conservation. Annals of Translational Medicine. 2015 Apr;3(6).

13. Pabinger I, Fries D, Schöchl H, Streif W, Toller W. Tranexamic acid for treatment and prophylaxis of bleeding and hyperfibrinolysis. Wiener klinische Wochenschrift. 2017 May 1;129(9-10):303-16.

14. Haoyang W, Pengde K, Fuxing P. Study on the efficacy and safety of tranexamic acid on perioperative blood loss in total hip replacement. Chinese. J. Bone. Joint. 2015; 4(08): 649-654.

15. Joseph T. Moskal, Susan G. Capps.Intra-articular Tranexamic Acid in Primary Total Knee 
Arthroplasty: Meta-analysis. J Knee Surg. 2018; 31(01): 056-067.

16. Fillingham YA, Ramkumar DB, Jevsevar DS, Yates AJ, Shores P, Mullen K, Bini SA, Clarke HD, Schemitsch E, Johnson RL, Memtsoudis SG. The safety of tranexamic acid in total joint arthroplasty: a direct meta-analysis. The Journal of arthroplasty. 2018 Oct 1;33(10):3070-82.

17. Guerreiro JP, Badaro BS, Balbino JR, Danieli MV, Queiroz AO, Cataneo DC. Application of tranexamic acid in total knee arthroplastyprospective randomized trial. The open orthopaedics journal. 2017;11:1049.

18. Wong J, Abrishami A, El Beheiry H, Mahomed NN, Davey JR, Gandhi R, Syed KA, Hasan SM, De
Silva Y, Chung F. Topical application of tranexamic acid reduces postoperative blood loss in total knee arthroplasty: a randomized, controlled trial. JBJS. 2010 Nov 3;92(15):2503-13.

19. Yang ZG, Chen WP, Wu LD. Effectiveness and safety of tranexamic acid in reducing blood loss in total knee arthroplasty: a meta-analysis. JBJS. 2012 Jul 3;94(13):1153-9.

20. Yen SH, Lin PC, Chen B, Huang CC, Wang JW. Topical tranexamic acid reduces blood loss in minimally invasive total knee arthroplasty receiving rivaroxaban. BioMed research international. 2017 Dec 19;2017. 